\title{
Tendências das séries históricas do índice de calor no município de Santa Maria - RS
}

\author{
Trends of historical series of the heat index in Santa Maria - RS, Brazil
}

Stefanía Dalmolin da Silva ${ }^{\mathrm{I}}$ Nereu Augusto Streck ${ }^{\mathrm{II}}$

\section{RESUMO}

Este trabalho teve como objetivo calcular $e$ analisar as séries históricas mensais do Índice de Calor (IC) para Santa Maria, RS, Brasil, no período de 1968 a 2011. As variáveis meteorológicas utilizadas neste trabalho foram pressão atmosférica, temperatura do bulbo seco e temperatura do bulbo úmido, no horário das $9 \mathrm{~h}$ (12UTC), $15 \mathrm{~h}$ (18UTC) e $21 \mathrm{~h}$ (00UTC). Foi realizada análise de tendência das séries históricas para o valor absoluto e a média mensais do IC através do teste de MannKendall e análise de regressão linear simples para quantificar a tendência, com nível de significância de 95\% $(\alpha=0,05)$. Para o valor máximo, no horário das 15 h (18UTC), as séries históricas para os meses de janeiro e abril apresentaram acréscimo no valor do índice de calor na magnitude de $0,76^{\circ} \mathrm{C}$ década ${ }^{-1}$ e $0,92^{\circ} \mathrm{C}$ década ${ }^{-1}$, respectivamente. No horário das $21 \mathrm{~h}$ (00 UTC), os meses de abril e novembro apresentaram aumento de $0,43^{\circ} \mathrm{C}$ décad $a^{-1}$ e $0,55^{\circ} \mathrm{C}$ década ${ }^{-1}$, respectivamente. Porém os meses de maio e agosto apresentaram diminuição de $0,69^{\circ} \mathrm{C}$ década $a^{-1}$ e $0,31^{\circ} \mathrm{C}$ década ${ }^{-1}$, respectivamente.

Palavras-chave: desconforto humano, Mann-Kendall, saúde humana.

\section{ABSTRACT}

The objective of this study was to calculate and analyze the monthly time series of the Heat Index (HI) for Santa Maria, RS, Brazil, during the period from 1968 to 2011. The meteorological variables used in this study were atmospheric pressure, dry-bulb temperature and wet-bulb temperature at 9am (12UTC), 3pm (18UTC) and 9pm (0OUTC). Analysis was performed using the highest absolute and the annual average value of the HI. Trends were tested with the Mann-Kendal test and the magnitude of the trend with the linear regression analysis at 95\% $(\alpha=0.05)$. At $3 p m$ (18UTC), the historical series of monthly maximum Heat Index in January and April had an increase of $0.76^{\circ} \mathrm{C}$ decade ${ }^{-1}$ and $0.92^{\circ} \mathrm{C}$ decade $^{-1}$, respectively. At 9pm (00UTC), April and November presented an increase of $0.43^{\circ} \mathrm{C}$ decade ${ }^{-1}$ e $0.55^{\circ} \mathrm{C}$ decade $e^{-1}$, respectively. However, May and August showed a decrease of $0.69^{\circ} \mathrm{C}$ decade ${ }^{-1}$ and $0.31^{\circ} \mathrm{C}$ decade $e^{-1}$, respectively.

Key words: human discomfort, Mann-Kendall, human health.

\section{INTRODUÇÃO}

Ao longo da história da humanidade, as sociedadessofreramimportantes consequências doclima, ora favorecendo o estabelecimento de civilizações sobre determinados espaços, ora determinando o sofrimento e desespero, forçando a adaptação ou a migração de grupos ou civilizações inteiras (MENDONÇA, 2000). Mudanças bruscas nas condições de tempo podem prejudicar diversos setores da sociedade, tanto no meio rural como no urbano, afetando, por exemplo, a saúde humana (CONCEIÇÃO, 2006). No meio rural, em especial, eventos meteorológicos extremos têm particular impacto, pois os trabalhadores rurais desempenham suas atividades na maior parte do tempo a campo, ao ar livre, ou seja, estão expostos diretamente aos efeitos de fenômenos meteorológicos. Assim, a condição de exposição direta é muito mais favorável à ocorrência de problemas de saúde nos trabalhadores rurais do que nos trabalhadores urbanos que, em consequência, são motivos justificáveis para ausência no trabalho e assim fazem aumentar os custos de produção ao empregador rural, com potencial impacto no preço do produto ao consumidor.

IPrograma de Pós-graduação em Engenharia Agrícola (PPGEA), Centro de Ciências Rurais (CCR), Universidade Federal de Santa Maria (UFSM), Santa Maria, RS, Brasil.

IIDepartamento de Fitotecnia, UFSM, Av. Roraima, 1000, 97105-900, Santa Maria, RS, Brasil. E-mail: nstreck2@yahoo.com.br. Autor para correspondência. 
O Índice de Calor (IC), ou também chamada de temperatura aparente, é uma medida que se relaciona ao desconforto para os seres humanos por níveis elevados de temperatura e umidade atmosférica, proposta por STEADMAN (1979, 1984). A premissa básica no IC é que, com a evaporação do suor, o corpo resfria-se, devido ao consumo de calor latente na superfície da pele e que, altos valores de umidade relativa do ar diminuem a taxa de evaporação, fazendo o corpo reter mais calor e assim causando desconforto (DELWORTH et al., 1999). O IC é um índice biometeorológico válido e preferencialmente deve ser usado nas seguintes condições (STEADMAN, 1979): a temperatura do bulbo seco deve ser acima de $20^{\circ} \mathrm{C}$ e abaixo de $50^{\circ} \mathrm{C}$ e velocidade do vento fraco (menor ou igual a $2,5 \mathrm{~m}$ $\mathrm{s}^{-1}$ ) em condições de sombra. O IC é um índice de desconforto humano facilmente calculado a partir de dados meteorológicos de estações convencionais ou automáticas, pois a temperatura e a umidade relativa do ar são variáveis medidas no interior do abrigo meteorológico.

Utilizando o IC, YIP et al. (2008) analisaram o impacto de eventos de calor excessivo sobre a taxa de mortalidade de pessoas no Condado de Maricopa, no Arizona, EUA, no período de 2000 a 2005. O IC também foi usado em Nápoles, na Itália, para analisar os impactos da forte onda de calor que ocorreu em 2003 na Europa (CRISTO et al., 2007). No Paquistão, ZAHID \& RASUL (2010) relatam que o aumento na temperatura do ar juntamente com a umidade relativa levou ao aumento no IC durante o verão, no período 1961 a 2007.

Com o aumento de evidências de alterações de temperatura e precipitação em alguns locais do Rio Grande do Sul (SANSIGOLO \& KAYANO, 2010; PBMC, 2013), é oportuno analisar as séries históricas de índices climáticos, incluindo índices de (des)conforto humano, como o IC. Considerando que as atividades agrícolas são realizadas quase que exclusivamente durante o período diurno e os trabalhadores precisam usar roupas longas para se proteger da elevada radiação solar, é nas horas mais quentes do dia que ocorre maior desgaste e perda de eficiência dos trabalhadores rurais. Assim, o IC é um índice apropriado para quantificar o nível de desconforto durante a jornada de trabalho nas atividades rurais, pois leva em conta as condições térmicas e a demanda evaporativa do ar.

Este trabalho teve como objetivo calcular e analisar as séries históricas do Índice de Calor para Santa Maria, RS, no período de 1968 a 2011.

\section{MATERIAL E MÉTODOS}

Este estudo foi realizado para a cidade de Santa Maria, RS, Brasil, através das observações realizadas na estação meteorológica do INMET (latitude: -29॰41'03', longitude: -5348'25', altitude: 95m). Segundo a classificação de Köppen, a região possui clima $\mathrm{Cfa}$ (subtropical úmido sem estação seca definida e com verões quentes), com temperatura média anual máxima de $24,8^{\circ} \mathrm{C}$, temperatura média anual mínima de $14,3^{\circ} \mathrm{C}$ e média anual de precipitação igual a $1686 \mathrm{~mm}$. Santa Maria está localizada na região fisiográfica da Depressão Central, no centro geográfico do Rio Grande do Sul. A cidade sede do município tem 262.368 mil habitantes e vários municípios vizinhos ao município de Santa Maria tem na agricultura a principal fonte de arrecadação municipal e de sustento para as famílias.

As variáveis meteorológicas utilizadas foram pressão atmosférica, temperatura do ar de bulbo seco e temperatura do ar de bulbo úmido, no horário das 9h (12UTC), 15h (18UTC) e 21h (00UTC), medidas diariamente na estação meteorológica convencional no $8^{\circ}$ DISME/INMET, no período de 1968 a 2011. A estação meteorológica está localizada no Campus da Universidade Federal de Santa Maria (UFSM) a aproximadamente $5 \mathrm{~km}$ da cidade de Santa Maria, em uma área do Departamento de Fitotecnia da UFSM, onde são realizados experimentos agrícolas com diferentes culturas, ou seja, a estação meteorológica está localizada em uma área típica da região agrícola do município de Santa Maria e municípios vizinhos. A qualidade dos dados foi analisada mensalmente, excluindo-se os dados fora do envelope de dois desvios-padrão da média da série histórica de cada variável meteorológica. Por este critério, foram excluídos no total 4838 dados que incluíram pressão atmosférica, temperatura do bulbo seco e úmido, para os três horários, o que corresponde a $10,1 \%$. Foram usados apenas dias com temperatura do bulbo seco acima de $20^{\circ} \mathrm{C}$, que é o limite inferior a partir do qual o IC deve ser usado como índice de desconforto humano (STEADMAN, 1979).

A umidade relativa (UR) foi calculada pela equação usada por PEREIRA et al. (2002):

$$
U R \%=\frac{e_{a}}{e_{s}} .100 \%
$$

em que e e e são, respectivamente, a pressão atual e de saturação do ar à temperatura do ar do bulbo seco (hPa) calculadas pelas Equações Psicrométrica e de Tetens, respectivamente: 


$$
e_{s}=6,108 \cdot 10^{\left(\frac{7,5 T_{s}}{237,3+T_{s}}\right)}
$$

em que $\mathrm{T}_{\mathrm{s}}$ é a temperatura do bulbo seco $\left({ }^{\circ} \mathrm{C}\right) \mathrm{e}$

$$
e_{a}=e_{s u}-A \cdot P\left(T_{s}-T_{u}\right)
$$

em que $e_{\mathrm{su}}$ é a pressão de saturação do vapor d'água do ar na temperatura do bulbo úmido, (hPa), A é a constante psicrométrica (neste estudo, o psicrômetro é do tipo não-ventilado, com $\mathrm{A}=0,0008^{\circ} \mathrm{C}^{-1}, \mathrm{P}$ é a pressão atmosférica $(\mathrm{hPa})$ e $\mathrm{T}_{\mathrm{u}}$ é a temperatura do ar medida no termômetro de bulbo úmido $\left({ }^{\circ} \mathrm{C}\right)$.

$\mathrm{O}$ índice de calor $\left(\mathrm{IC},{ }^{\circ} \mathrm{C}\right)$ foi calculado segundo STEADMAN (1979):

$\mathrm{IC}=-42,379+2,04901523 \cdot \mathrm{T}+10,14333127 . \mathrm{UR}-$ $6,83783 \cdot 10^{-3} \cdot T^{2}-5,481717 \cdot 10^{-2} \cdot U^{2}+1,22874 \cdot 10^{-3}$. $\mathrm{T}^{2} \cdot \mathrm{UR}+8,5282 \cdot 10^{-4} \cdot \mathrm{T} \cdot \mathrm{UR}-1,99 \cdot 10^{-6} \cdot \mathrm{T}^{2} \cdot \mathrm{UR}^{2}$

em que T é a temperatura do ar $\left({ }^{\circ} \mathrm{F}\right)$ e UR é a umidade relativa do ar (\%).

As curvas teóricas do IC x Temperatura para as UR de 20, 40, 60, 80 e 100\% estão na figura 1 . Os níveis de alerta para faixas do IC e possíveis problemas na saúde decorrente da exposição humana são (NOAA, 2013): para exposição a IC igual ou acima de $54^{\circ} \mathrm{C}$ (denominado Perigo Extremo) poderá haver a ocorrência de insolação e risco de Acidente Vascular Cerebral iminente; para IC na faixa de 41,1 a $53,9^{\circ} \mathrm{C}$ (Perigo) possibilidade de insolação, câimbras musculares e / ou exaustão, com possível dano cerebral com a exposição e / ou atividade física prolongada; para faixa entre 32,1 a $41^{\circ} \mathrm{C}$ (Extrema Cautela), possíveis câimbras, insolação e exaustão para exposição prolongada e/ou atividade física; quando IC for entre 27,1 e $32^{\circ} \mathrm{C}$ (Cautela), possível fadiga em casos de exposição prolongada e atividade física; quando o IC for abaixo de $27^{\circ} \mathrm{C}$ não há alerta.

Foi analisado o maior valor absoluto e a média do IC, para os três horários para cada mês do ano da série histórica. A tendência nas séries mensais de IC foi testada pelo teste não paramétrico de MannKendall, com nível de significância de 95\% $(\alpha=0,05)$. Nas séries em que a tendência foi significativa, a magnitude da tendência foi quantificada por análise de regressão linear simples, em que o coeficiente

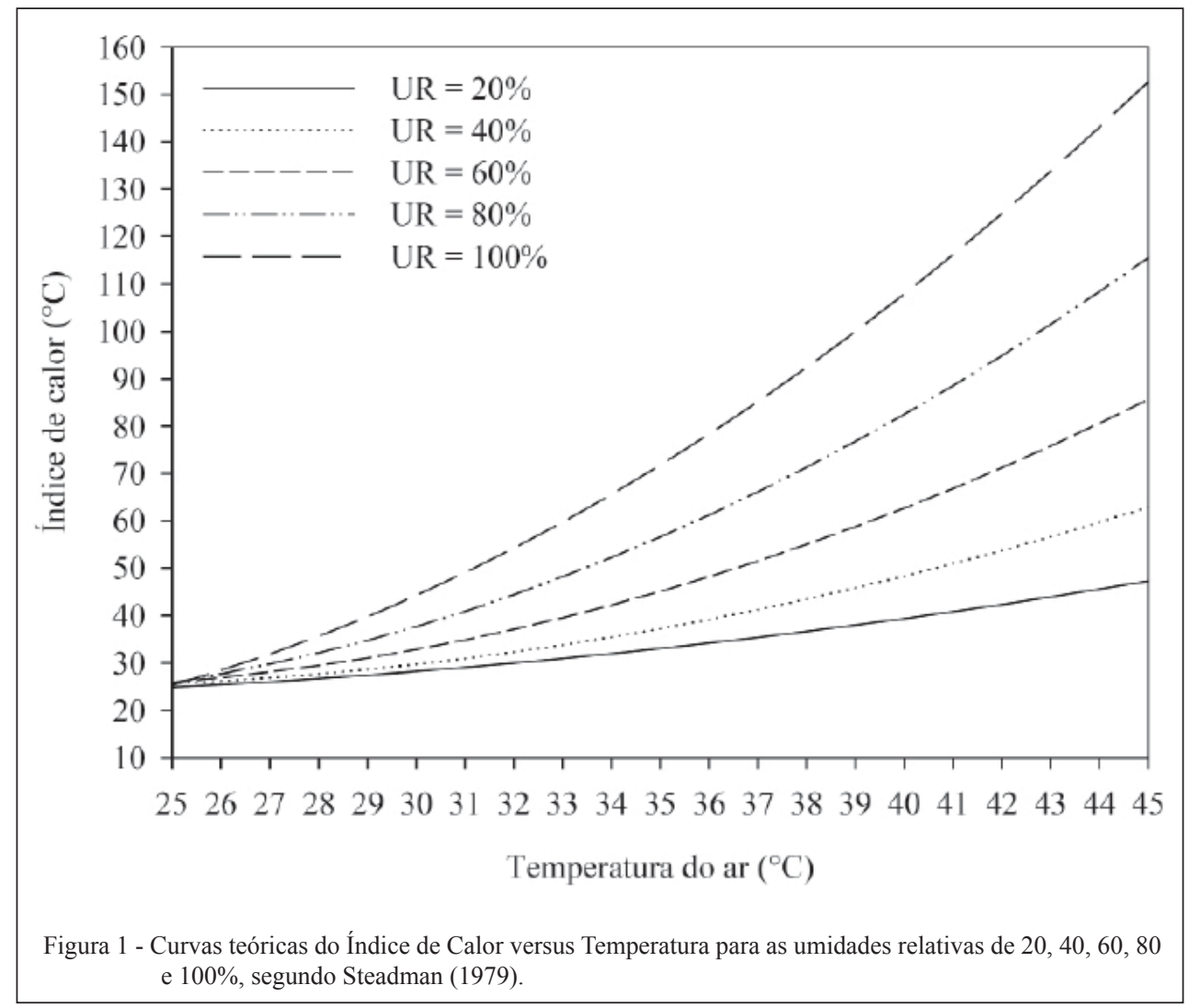

Ciência Rural, v.44, n.8, ago, 2014. 
da regressão é testado pelo teste $\mathrm{F}$ com $\alpha=0,05$ (SANSIGOLO \& KAYANO, 2010).

\section{RESULTADOS E DISCUSSÃO}

$\mathrm{Na}$ figura 2, estão apresentadas as séries dos valores máximos absolutos e médios mensais do índice de calor no horário das $15 \mathrm{~h}$ (18UTC). No verão, os valores de IC variaram entre $34^{\circ} \mathrm{C}$ a $44^{\circ} \mathrm{C}$, classificados como extrema cautela a perigo (NOAA,
2013), respectivamente (Figura 2A, 2B, 2L). Nos meses de março e abril, ainda houve a ocorrência de IC entre $27^{\circ} \mathrm{C}$ a $42^{\circ} \mathrm{C}$ (Figura $2 \mathrm{C}$ e $2 \mathrm{D}$ ). Nos meses de outono, inverno e primavera, o IC variou entre $28^{\circ} \mathrm{C}$ a $35^{\circ} \mathrm{C}$ (Figura 2E, 2F, 2G, 2H, 2I, 2J e $2 \mathrm{~K}$ ). As séries históricas do índice de calor para os meses de janeiro e abril apresentaram aumento de $0,76^{\circ} \mathrm{C}$ década $^{-1}$ e $0,92^{\circ} \mathrm{C}$ década $^{-1}$, respectivamente (Figura 2A e 2D). O aumento para o mês de janeiro foi causado devido ao aumento da temperatura
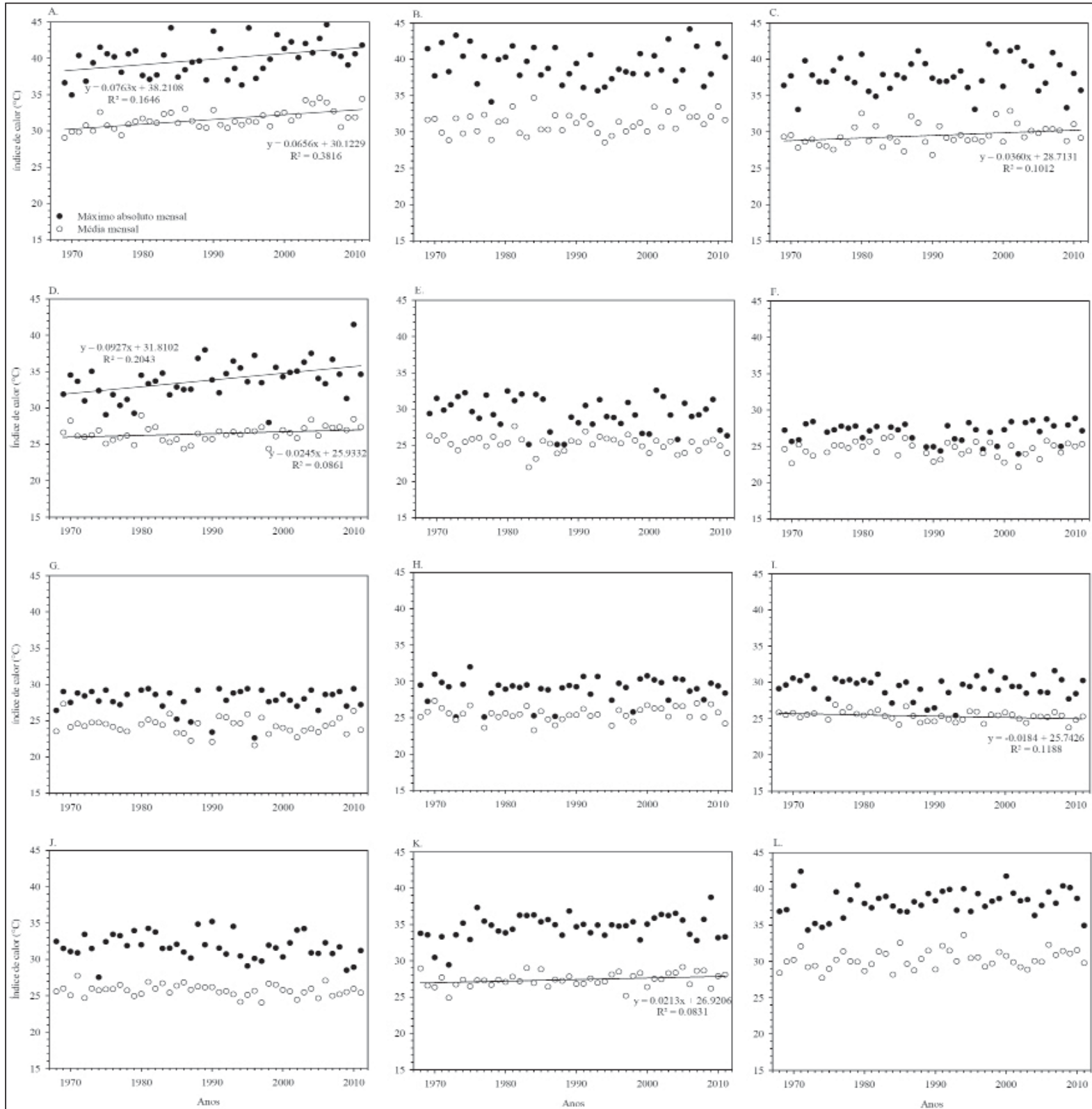

Figura 2 - Séries históricas do Índice de Calor (valor máximo absoluto e média) nos meses de janeiro (A), fevereiro (B), março (C), abril (D), maio (E), junho (F), julho $(\mathrm{G})$, agosto $(\mathrm{H})$, setembro (I), outubro (J), novembro (K) e dezembro (L), para o horário das $15 \mathrm{~h}$ (18 UTC), durante o período de 1968 a 2011 em Santa Maria, RS. 
do bulbo seco e, no mês de abril, foi o aumento na umidade relativa que ocasionou o aumento no IC. Com relação aos valores médios mensais no horário da tarde, a série histórica dos meses de janeiro, março, abril e novembro apresentaram aumento significativo de $0,65^{\circ} \mathrm{C}$ década $^{-1}, 0,36^{\circ} \mathrm{C}$ década $^{-1}, 0,24^{\circ} \mathrm{C}$ década $^{-1}$ e $0,21^{\circ} \mathrm{C}$ década $^{-1}$, respectivamente. Nestas séries, o aumento do IC foi devido ao aumento da temperatura do ar (janeiro e novembro), da umidade relativa (março) e de ambas umidade relativa e temperatura do ar (abril) (Figura 2A, $2 \mathrm{C}, 2 \mathrm{D}$ e $2 \mathrm{~K})$. O mês de setembro teve diminuição de $0,18^{\circ} \mathrm{C}$ década $^{-1}$ (Figura 2I).

Os valores do coeficiente do teste de MannKendall e sua probabilidade estão na tabela 1. Para o valor máximo absoluto mensal do IC, foi encontrada tendência positiva e nível de significância de $5 \%$ de probabilidade de erro nas séries de janeiro e abril (18UTC) e abril e novembro (00UTC). As séries que apresentaram tendência negativa e significativa a 5\% foram maio e agosto (no horário 00UTC). Todas as outras séries de máximos absolutos mensais de IC não tiveram tendência (Tabela 1).
No horário das 9h (12UTC), os menores valores máximos absolutos do IC foram no outono, inverno e primavera (dados não mostrados). Nestas estações do ano, o valor do IC variou entre $16^{\circ} \mathrm{C}$ a $25^{\circ} \mathrm{C}$. No verão, o IC neste horário atingiu valores entre $25^{\circ} \mathrm{C}$ a $33^{\circ} \mathrm{C}$, identificados como cautela ou extrema cautela, tendo como principais consequências exaustão devido à exposição prolongada e insolação (NOAA, 2013). O dia/mês/ano com maior valor de IC foi $09 / \mathrm{jan} / 2005$, com $33,96^{\circ} \mathrm{C}$, seguido por $07 /$ fev/2003, com $33,72^{\circ} \mathrm{C}$, e por $12 / \mathrm{dez} / 1994$, com $33,12^{\circ} \mathrm{C}$, valores classificados como alerta de extrema cautela (NOAA, 2013). Nenhuma das séries de IC no horário da manhã tiveram tendência de aumento ou diminuição, ou seja, as séries são estacionárias. Com relação às séries mensais com valores médios no horário da manhã, a série histórica do mês de março teve aumento de $0,28^{\circ} \mathrm{C}$ década $^{-1}$, decorrente do aumento na temperatura do ar. O maior valor do IC $\left(16,9^{\circ} \mathrm{C}\right)$ foi no mês de fevereiro de 1984 .

Tabela 1 - Valores do coeficiente do Teste de Mann-Kendall e sua probabilidade para a série histórica do Índice de calor, às 9h (12UTC), 15h (18UTC) e 21h (00UTC), em Santa Maria, RS, no período de 1968 a 2011.

\begin{tabular}{|c|c|c|c|c|c|c|c|}
\hline \multirow{2}{*}{ Mês } & \multirow{2}{*}{ Série } & \multicolumn{2}{|c|}{-----------9h (12UTC) -------- } & \multicolumn{2}{|c|}{----------15h (18UTC) -------- } & \multicolumn{2}{|c|}{----------21h (00UTC)----- } \\
\hline & & Coef. & Prob. & Coef. & Prob. & Coef. & Prob. \\
\hline \multirow[t]{2}{*}{ Janeiro } & Máximo & 0.0897 & 0.3966 & 0.2668 & $0.0117 *$ & 0.0985 & 0.3516 \\
\hline & Média & 0.1650 & 0.1189 & 0.4374 & $0.0001 *$ & 0.1805 & 0.0880 \\
\hline \multirow[t]{2}{*}{ Fevereiro } & Máximo & 0.0431 & 0.6832 & -0.0498 & 0.6377 & 0.0210 & 0.8424 \\
\hline & Média & 0.1428 & 0.1770 & 0.1539 & 0.1458 & 0.0852 & 0.4203 \\
\hline \multirow[t]{2}{*}{ Março } & Máximo & -0.0299 & 0.7775 & 0.0675 & 0.5232 & 0.0832 & 0.5956 \\
\hline & Média & 0.2225 & $0.0354 *$ & 0.2314 & $0.0287 *$ & 0.1054 & 0.5008 \\
\hline \multirow[t]{2}{*}{ Abril } & Máximo & -0.1024 & 0.3454 & 0.3178 & $0.0027 *$ & 0.2336 & $0.0272 *$ \\
\hline & Média & -0.2048 & 0.0600 & 0.2713 & $0.0103 *$ & 0.0742 & 0.4832 \\
\hline \multirow[t]{2}{*}{ Maio } & Máximo & -0.0492 & 0.6871 & -0.1760 & 0.0961 & -0.2233 & $0.0484 *$ \\
\hline & Média & 0.0113 & 0.9259 & -0.1827 & 0.0842 & -0.1465 & 0.1954 \\
\hline \multirow[t]{2}{*}{ Junho } & Máximo & -0.1935 & 0.1195 & 0.0804 & 0.4585 & 0.1957 & 0.1219 \\
\hline & Média & -0.1169 & 0.3469 & -0.0146 & 0.8928 & 0.0623 & 0.6221 \\
\hline \multirow[t]{2}{*}{ Julho } & Máximo & -0.1264 & 0.3265 & 0.0011 & 0.9913 & -0.1657 & 0.1680 \\
\hline & Média & -0.0666 & 0.6049 & -0.1056 & 0.3240 & 0.0017 & 0.9882 \\
\hline \multirow[t]{2}{*}{ Agosto } & Máximo & 0.0069 & 0.9573 & 0.0313 & 0.7698 & -0.2172 & $0.0515^{*}$ \\
\hline & Média & -0.1724 & 0.1809 & 0.0685 & 0.5226 & -0.3252 & $0.0036^{*}$ \\
\hline \multirow[t]{2}{*}{ Setembro } & Máximo & -0.0924 & 0.4348 & -0.0897 & 0.3966 & 0.0360 & 0.7369 \\
\hline & Média & -0.0890 & 0.4516 & -0.2336 & $0.0272 *$ & 0.1173 & 0.2737 \\
\hline \multirow[t]{2}{*}{ Outubro } & Máximo & -0.1080 & 0.3135 & -0.1649 & 0.1146 & 0.0909 & 0.3844 \\
\hline & Média & -0.1916 & 0.0737 & -0.1479 & 0.1568 & -0.0718 & 0.4916 \\
\hline \multirow[t]{2}{*}{ Novembro } & Máximo & 0.0887 & 0.3955 & 0.1627 & 0.1193 & 0.3488 & $0.0008^{*}$ \\
\hline & Média & 0.0063 & 0.9516 & 0.2367 & $0.0235^{*}$ & 0.0528 & 0.6131 \\
\hline \multirow[t]{2}{*}{ Dezembro } & Máximo & 0.1374 & 0.1886 & 0.1374 & 0.1886 & 0.0845 & 0.4184 \\
\hline & Média & 0.1902 & 0.0687 & 0.1902 & 0.0687 & 0.0338 & 0.7462 \\
\hline
\end{tabular}

*Significativo a $5 \%$. 
Com relação às séries de valores máximos absolutos do índice de calor no horário das $21 \mathrm{~h}$ (00UTC) (dados não mostrados), no verão, os valores variaram entre $26^{\circ} \mathrm{C}$ a $34^{\circ} \mathrm{C}$, identificados como sem alerta a extrema cautela (NOAA, 2013) e nos meses de outono, inverno e primavera, o IC variou entre $15^{\circ} \mathrm{C}$ a $30^{\circ} \mathrm{C}$. As séries históricas dos meses de abril e novembro tiveram aumento de $0,43^{\circ} \mathrm{C}$ década $^{-1}$ e $0,55^{\circ} \mathrm{C}$ década $^{-1}$, respectivamente, e o aumento foi causado devido ao aumento tanto da umidade relativa como da temperatura do ar. Já as séries históricas do IC de valores máximos absolutos para os meses de maio e agosto tiveram diminuição de $0,69^{\circ} \mathrm{C}$ década $^{-1}$ e $0,31^{\circ} \mathrm{C}$ década $^{-1}$, respectivamente, ambos devido a uma diminuição na temperatura do ar. Para as séries de IC mensais no horário das 21h (00UTC), o único mês com tendência, que foi negativa, foi agosto, com magnitude de $0,68^{\circ} \mathrm{C}$ década $^{-1}$.

Comparando-se o IC nos três horários do dia, em todos os meses a sequência foi: 15h (18UTC) $>21 \mathrm{~h}($ 00UTC) $>9 \mathrm{~h}$ (12UTC). Sob o ponto de vista de desconforto, o horário das $15 \mathrm{~h}$ (18UTC) é o mais crítico para os trabalhadores rurais, que realizam sua jornada de trabalho durante o período diurno e a céu aberto. Para os trabalhadores urbanos, o efeito do desconforto externo é menor, pois boa parte deles trabalha em ambientes internos, em geral, climatizados. Mesmo assim, nas médias e grandes cidades, como Santa Maria, o número de pessoas visitando a cidade, por motivos diversos, é grande e seu deslocamento nas ruas durante o horário comercial (inclusive durante a tarde) causa exposição ao IC externo. Nos centros urbanos, especialmente nos grandes centros, há ainda um efeito local adicional pela ilha de calor urbana, que pode aumentar significativamente a temperatura do ar (PRICE, 1979; OKE, 1987; FREITAS \& DIAS, 2005) e, portanto, o desconforto para quem transita pelas ruas nas horas mais quentes do dia é ainda maior que o IC calculado a partir dos dados da estação meteorológica. Os resultados para Santa Maria indicam que, durante as tardes nos meses de verão, o desconforto medido pelo IC é elevado (Figura 2A, 2B e $2 \mathrm{~L}$ ), ultrapassando $40^{\circ} \mathrm{C}$ nos três meses (dezembro, janeiro e fevereiro). Neste período do ano, muitos habitantes que moram e trabalham na cidade estão em período de férias, mas, no meio rural, é neste período que se intensificam as atividades, pois é a época em que as culturas de verão (soja, milho, arroz, fumo) estão em pleno crescimento e os trabalhadores rurais estão no auge de suas atividades, realizando os tratos culturais, como aplicação de agrotóxicos (inseticidas, fungicidas e herbicidas), manejo de água de irrigação (no caso do arroz), adubação nitrogenada em cobertura e colheita (no caso do fumo, a colheita é totalmente manual). Nesse contexto, a tendência de aumento do IC no horário das 15h (18UTC) no mês de janeiro (Figura 2A) é preocupante para os trabalhadores rurais.

A análise de tendência nas séries históricas de IC indicou que, das 76 séries analisadas, nove apresentam tendência de aumento e quatro apresentaram tendência de diminuição. As que apresentaram tendência de aumento foram no horário da manhã (uma), tarde (seis) e noite (duas) e as que tiveram tendência de diminuição foram a tarde (uma) e a noite (três). Esses resultados indicam que o período da tarde tem maior elevação do IC nas últimas quatro décadas em Santa Maria, seguido pelo período da noite a manhã.

Trabalhos anteriores indicam que um aumento no IC não apenas contribuirá para o aumento do desconforto nos seres humanos, mas também pode afetar a fauna e flora da região (ZAHID \& RASUL, 2010). Também há relatos que mortes de pessoas ocorridas devido ao desconforto térmico ocorreram quando o índice de calor atingiu valores acima de $37,8^{\circ} \mathrm{C}$ em 11 dias consecutivos (YIP et al., 2008). Assim, o fato de ter havido séries com aumento do IC nas últimas quatro décadas em Santa Maria é uma preocupação adicional para o bem estar das pessoas.

O IC, por ser um índice de desconforto por temperatura e umidade relativa elevadas, é um índice importante nas regiões úmidas tropicais e durante os meses de verão nas regiões extratropicais úmidas (DELWORTH et al., 1999), como o sul do Brasil. Os resultados deste estudo indicam que na região central do Rio Grande do Sul, representado por Santa Maria, houve um aumento no IC em janeiro no horário das $15 \mathrm{~h}$, tanto para o valor máximo absoluto mensal (Figura 2A) como para a média mensal (Figura 2A). Destaca-se ainda o mês de novembro, que também teve tendência de aumento no índice de calor nas últimas quatro décadas. Estes resultados concordam com os obtidos por DELWORTH et al. (1999) que, com um modelo climático acoplado oceano-atmosfera, construíram a série temporal do IC durante 300 anos (1765-2065) durante o verão, na região Sudeste dos Estados Unidos, uma região com temperatura e umidade relativa similar à região sul do Brasil, na qual é evidente o aumento do índice de calor a partir da década de 1960, que foi atribuído pelos autores ao aumento da temperatura nas últimas quatro décadas do século XX.

Se as projeções de aumento de temperatura para o século XXI projetadas para o Brasil e o Rio Grande do Sul (PBMC, 2013), vierem também acompanhadas 
de aumento no conteúdo de água na atmosfera, o que é bastante provável (DELWORTH et al., 1999), o IC e, portanto o desconforto humano, pode aumentar em uma taxa maior do que a taxa de aumento da temperatura durante este século, pois o efeito do resfriamento do corpo humano é inibido pela alta umidade do ar. Este efeito é mais pronunciado nas regiões tropicais e extratropicais úmidas, onde o Rio Grande do Sul está incluído. Portanto, poderá haver um efeito adicional ao aquecimento global em termos de desconforto humano para trabalhadores, principalmente os rurais.

\section{CONCLUSÃO}

Para Santa Maria, Rio Grande do Sul, as séries históricas do Índice de calor máximo absoluto mensal dos meses de janeiro e abril às 15h (18UTC) e abril e novembro às $21 \mathrm{~h}$ (00UTC) apresentam tendência positiva significativa, enquanto as séries históricas dos meses de maio e agosto apresentam tendência negativa. Para os trabalhadores rurais, que realizam práticas de manejo nas culturas de verão, o mês de janeiro tem maior desconforto térmico.

Nas séries históricas do Índice de calor médio mensal, nos meses de março às $9 \mathrm{~h}$, janeiro, março, abril e novembro às $15 \mathrm{~h}$ (18UTC) apresentam tendência positiva significativa, enquanto as séries dos meses de setembro às $15 \mathrm{~h}$ (18UTC) e agosto às $21 \mathrm{~h}$ (00UTC) apresentam tendência negativa.

As demais séries mensais de índice de calor em Santa Maria não apresentam tendência, ou seja, são estacionárias.

\section{REFERÊNCIAS}

CONCEIÇÃO, R.A.F.; BITENCOURT, D.P. Análise de um período quente no estado de Santa Catarina através do cálculo do Índice de Calor. In: CONGRESSO BRASILEIRO DE METEOROLOGIA, 14, 2006, Florianópolis, SC. Anais... Florianópolis: Sociedade Brasileira de Meteorologia, 2006. Disponível em: <http://www. cbmet.com/cbm-files/14-50835d43c5dcd181de6745035c2a0f63. pdf $>$ Acesso em: 18 jul. 2013.

CRISTO, R.D. et al. An analysis of heat index over Naples (Southern Italy) in the context of European heat wave 2003. Natural Hazards, v.40, p.373-379, 2007. Disponível em: <http:// link.springer.com/article/10.1007/s11069-006-0033-7>. Acesso em: 17 mar. 2011. doi: 10.1007/s11069-006-0033-7.

DELWORTH, T.L. et al. Changes in heat index associated with CO2-induced global warming. Climatic Change, v.43, p.369386, 1999. Disponível em: <http://link.springer.com/article/ 10.1023/A:1005463917086>. Acesso em: 17 mar. 2011. doi: 10.1023/A:1005463917086.

FREITAS, E.D.; SILVA DIAS, P.L. Alguns efeitos de áreas urbanas na geração de uma ilha de calor. Revista Brasileira de Meteorologia, v.20, n.3, p.355-366, 2005. Disponível em: $<$ http://www.rbmet.org. $\mathrm{br} /$ port $/$ revista/revista_artigo.php?id_artigo $=140>$. Acesso em: 15 ago. 2013.

MENDONÇA, F.A. Aspectos da interação clima-ambiente-saúde humana: da relação sociedade-natureza à (in)sustentabilidade ambiental. RA' EGA (UFPR), v.4, p.85-100, 2000. Disponível em: <http://www.unit.br/mestrado/saudeambiente/ leitura2008/Clima-Ambiente-Sa $\%$ C3\%BAde $\% 20$ Humana $\% 20$ (Mendon\%C3\%A7a\%202000).pdf>. Acesso em: 15 jan. 2013.

NOAA (National Oceanic and Atmospheric Administration). 2013. Disponível em: <http://www.nws.noaa.gov/os/heat/index.shtml > Acesso em: 18 jul. 2013.

OKE, T.R. Boundary layer climates. 2.ed. London: Routledge, 1987. 435 p.

PBMC (PAINEL BRASILEIRO DE MUDANÇAS CLIMÁTICAS). Contribuição do Grupo de Trabalho 1 ao Primeiro relatório de Avaliação Nacional do Painel Brasileiro de Mudanças Climáticas. Sumário Executivo GT1. PBMC. Rio de Janeiro, 2013. 24p. Disponível em: <http://www.pbmc.coppe. ufri.br/documentos/MCTI PBMC Sumario\%20Executivo\%204 Finalizado.pdf $>$. Acesso em: 7 out. 2013.

PEREIRA, A.R. et al. Agrometeorologia: Fundamentos e Aplicações Práticas. Guaíba: Livraria e Editora Agropecuária, 2002. 478p.

PRICE, J. Assessment of the urban heat island effect through the use of a satellite data. Monthly Weather Review, v.107, p.1.5541.557, 1979. Disponível em: <http://journals.ametsoc.org/doi/ abs/10.1175/1520-0493(1979)107\%3C1554\%3AAOTUHI\%3 E2.0.CO\%3B2>. Acesso em: 15 ago. 2013. doi: 10.1175/15200493(1979) $107<1554$

SANSIGOLO, C.A.; KAYANO, M.T. Trends of seasonal maximum and minimum temperatures and precipitation in Southern Brazil for the 1913-2006 period. Theorical and Applied Climatology, v.101, p.209-216, 2010. doi: 10.1007/s00704-010-0270-2.

STEADMAN, R.G. The assessment of sultriness. Part I: A temperature-humidity index based on human physiology and clothing science. Journal of Climate and Applied Meteorology, v.18, p.861-873, 1979. Disponível em: <http://link.springer.com/ article/10.1007/s00704-010-0270-2>. Acesso em: 15 ago. 2013. doi: 10.1175/1520-0450(1979)018<0861.

STEADMAN, R. G. A universal scale of apparent temperature. Journal of Climate and Applied Meteorology, v.23, p.16741687, 1984. Disponível em: <http://journals.ametsoc.org/doi/abs/ 10.1175/15200450(1984)023\%3C1674:AUSOAT\%3E2.0.CO;2>. Acesso em 15 jan. 2013. doi: 10.1175/1520-0450(1984)023<1674.

ZAHID, M.; RASUL, G. Rise in summer heat index over Pakistan. Pakistan Journal of Meteorology, v.6, p.85-96, 2010. Disponível em: <http://www.pmd.gov.pk/rnd/rnd files/vol6 issue12/8 Rise $\% 20$ in $\% 20$ Summer\%20Heat $\% 20$ Index $\% 20$ over\%20Pakistan.pdf>. Acesso em: 4 fev. 2012

YIP, F.Y. et al. The impact of excess heat events in Maricopa County, Arizona: 2000-2005. International Journal of Biometeorology, v.52, p.765-772, 2008. Disponível em: <http://link.springer.com/ article/10.1007/s00484-008-0169-0>. Acesso em: 31 mar. 2011. doi: 10.1007/s00484-008-0169-0. 